\title{
Address Terms in Classroom Discourse: A Case of University of Cape Coast Students in Ghana
}

\author{
Lena Awoonor-Aziaku \\ Institute for Phonetics Johann Wolfgang, Goethe University, Frankfurt am Main, Germany \\ Email: awooleen@gmail.com
}

How to cite this paper: Awoonor-Aziaku, L. (2021). Address Terms in Classroom Discourse: A Case of University of Cape Coast Students in Ghana. Open Journal of Modern Linguistics, 11, 497-510. https://doi.org/10.4236/ojml.2021.113037

Received: October 23, 2020

Accepted: June 27, 2021

Published: June 30, 2021

Copyright (c) 2021 by author(s) and Scientific Research Publishing Inc. This work is licensed under the Creative Commons Attribution International License (CC BY 4.0).

http://creativecommons.org/licenses/by/4.0/

(c) (i) Open Access

\begin{abstract}
Recent researches have focused on the use of address and reference terms in several social settings. The present study contributes to these works by examining the use of address terms in classroom interactions at the University of Cape Coast. Using a face-to-face interview and audio recording, this work examined address terms used among students and lecturers in real time situations. A total of 35 recorded lectures, coupled with interviews, were obtained and transcribed for the analysis. The analysis showed that students usually used title + last names (TLN), honorifics (Hon), and sometimes avoidance strategies when addressing lecturers in class. On the other hand, lecturers usually use first names (FN), nicknames, and also sometimes avoidance strategies when addressing students. The study has shown that the T/V distinction argued by Brown and Gilman (1960) is present in tertiary address systems in Ghana. In general, this work has pedagogical implications for sociolinguistic studies and other internal academic policies.
\end{abstract}

\section{Keywords}

Address, Classroom, Discourse, Honorific, Interaction, Settings, Strategies

\section{Introduction}

Forms of address and terms of reference are complicated terms in English and, indeed, in many other languages. The choice of address terms and reference terms is determined by several factors, ranging from religion, social and economic status of the participants in the social interactions, and also by social restrictions and religious taboos. The degrees of familiarity and formality between the speakers as well as the complex structure of society itself have contributed to the development of several forms of address. In recent years, there has been a growing interest in the relationship between linguistics and anthropology and a 
number of studies have been made to develop an ethnological approach to the semantic analysis of certain categories of lexical items as kinship, colour and food.

The way we address someone directly and how we refer to the same person in his/her absence are not always the same. The use of direct address formulae is most often governed by the relationship between the two participants: the speaker and the hearer. When choosing a term of reference, however, the speaker not only has to take into account his/her relationship with the hearer, but also he/she has to decide on how to present the referent in an appropriate manner. Both direct address and reference terms have been largely studied from a pragmatic and sociolinguistic point of view. Studies that have presented politeness as an integral factor that influences people's choice vary across the various linguistic fields.

Establishing social relationship between individuals is perhaps the first step to every communicative event. To do so, people may choose different techniques to open and further maintain, or close conversations. One important issue in studying communication is to learn how individuals manage to open conversations or how people address one another in a given language. A key human verbal behaviour in social interaction involves naming practices, which are more specifically and often considered in sociolinguistics as address terms and reference terms. An address term is seen as a linguistic expression used by interactants to designate each other in a one-on-one dyadic relationship (Oyetade, 1995). A reference term, however, is used to designate a human referent who is either present or not in a communicative encounter; it is usually nominative, rather than vocative. According to Dickey (1997), the linguistic item used to talk about a person in his/her absence (i.e., reference term) is not always the same as the one used to address him/her in a one-on-one encounter (i.e., address term).

The use of address terms manifests in so many different circles from social, political, religious and of course, academic circles. In the academic setting, classroom discourse has peculiar features which characterise its uniqueness. Among the characteristics are language choices and the power dynamics that hold mainly between students and lecturers. Clark and Clark (2008) note that a classroom discourse describes what happens in the classroom and it is an intricate socio-cultural process that involves techniques of meaning construction in the development of students' social identities. Teachers in the classrooms have a role to play as far as teaching and learning are concerned. This is because they control the learning objectives, styles and activities, and this ultimately affects the power relations and the address terms that are used in these settings. Therefore, it is of major importance to consider the roles and communication of teachers and students in the classroom.

\subsection{Address Terms in Academic Interactions}

The literature on address terms, following Brown and Gilman (1960), traditionally acknowledges a binary distinction between $\mathrm{V}$-forms and $\mathrm{T}$-forms to indicate formal and informal strategies of address. In this regard, English constitutes an 
exception amongst European languages for its lack of a T/V dichotomy in the pronominal system and of a grammatical codification of politeness in its verbs (Helmbrecht, 2013). For Cook (2014), the second-person pronoun you epitomises neutrality $(\mathrm{N})$ in address in the framework of analysis. Similarly, Clyne (2009: p. 38) maintain that you is a default neutral pronoun that "fulfils the functions of both $\mathrm{T}$ and $\mathrm{V}$ without being the equivalent of either". In the view of Wierzbicka (2003: p. 47), "[t]he English you keeps everybody at a distance" though not to the same extent as V-pronouns in other languages. In the academic context, the pronoun you can be exploited as an effective alternative to a formal title and an informal first name when addressing a lecturer. This strategy of avoidance in address practice is only apparently neutral, as the deliberate choice not to commit to either of the nominal forms offered by teachers may activate pragmatic inferences or feed asymmetry in classroom relations (Formentelli, 2009).

The T/V dichotomy in English is encoded lexically by means of nominal forms that can be ordered along a scale of respect/distance and intimacy/familiarity: from honorifics (sir, madam/ma'am), personal or professional titles ( $\mathrm{Mr}, \mathrm{Mrs}$, Ms, professor, doctor) generally followed by a last name or a full name, to first names and nicknames, and the large category of familiarisers to endearment terms (mate, buddy, guys, honey, sweetheart, love) (cf. Biber et al., 1999; Dunkling, 1990). To cite a significant example, the exchange of first names among newly acquainted people is now considered the norm in American English (Murray, 2002), while in British society it may still be perceived as awkward and inappropriate, especially by older generations (Bargiela et al., 2002).

One of the classic studies in the field of terms of address are those of Brown and Gilman (1960), and Brown and Ford (1961). In the former study, Brown and Gilman worked on Indo-European, and specifically Western European languages (French, German, Spanish, and Italian). They assumed that these languages have pronouns which could be used by participants in communication. They proposed the symbols $T$ and $V$ (from Latin $t u$ and $v o s$ ), with $T$ standing for the "familiar" second person pronoun and $V$ for the "polite" one in any language (Brown \& Gilman, 1960). In doing so, they highlighted the two important aspects of speakers' relations, power and solidarity, with regard to the choice of address terms.

The term "power semantic" is introduced, particularly, to explain how in the Middle Ages European $T / V$ pronouns were used differently by speakers. When inferiors addressed superiors, they used $V$ as a means of showing politeness and respect, and $T$ was used by superiors to address inferiors. The authors claimed that this kind of non-reciprocity and asymmetry relationship, which was common up to the 19th century, reflects the social life of those periods. By contrast, there was a reciprocity and symmetry relationship when members of the same group addressed each other. Upper class interlocutors usually used $V$ for each other, and lower-class speakers addressed each other with $T$. They thus believed that power has many bases: "physical strength, wealth, age, sex, institutionalized 
role in the church, the state, the army, or within the family" (Brown \& Gilman, 1960: p. 255). The results of their study show that the most common forms of address are the first name (FN) and the title plus last name (TLN) in American English which is contrary to Murphy (1988). They also found intimacy and status between interlocutors as the two major factors influencing the choice of the address terms. While FN was found to be reciprocal in most cases, TLN did occur at least at the beginning of acquaintance.

Bargiela et al. (2002), in their investigation of naming strategies in intercultural business encounters, focus on the frequent use of first names and informality on the part of English native speakers in addressing non-acquainted people. The authors claim that such politeness strategies of involvement are "an indicator of ease of communication with strangers" (2002: 1) for many British and American speakers. These strategies, however, can be offensive if employed in interactions with people from other linguistic and cultural backgrounds. In this paper, they argue that the growing informality of address in institutional encounters is relatively recent in the United Kingdom and is part of the process of Americanization of British culture.

They believe that not all British people are comfortable with the use of reciprocal first names in initial encounters and that this practice is still considered inappropriate by many speakers. As for the domain of academic interactions, Bargiela et al. (2002) suggest that the use of reciprocal first name with lecturers is common in British universities, but some students are not comfortable with it and find it too familiar. Hence, a certain amount of dispreference and resistance on the part of students in the use of informality in the classroom have been registered by students. This would contrast with one of the main points of Brown and Gilman's model, namely the rapid switch to mutual informal address. Moreover, it would necessarily require a revision of the distribution of power in the dyad, with a reassessment of the role of less powerful participants in regulating the evolution of the relationship towards informality.

McIntire (1972) found that students mostly preferred zero address terms when addressing lecturers, with only a few instances of TLN. She explained the use of zero address terms as symptomatic of confusion of norms. Murphy (1988) used questionnaires to elicit the kind of reference terms used by undergraduate university students in Brown University for faculty members and colleague students. He found that the speakers' choice of the terms was significantly influenced by factors such as speaker-referent relationship, addressee-referent relationship, and the presence of bystanders. He observed that a speaker would often shift from his or her original choice of reference term in order to adopt a term used by his addressee.

Formentelli (2009) attempted to find out whether the use the address terms by members of faculty and students in a British University was culturally influenced. His study largely confirmed some of the previous studies. His study however showed the presence of power, for example, vertical relationships such as student-lecturer interaction as significant influence on the choice of the ad- 
dress terms. That is, students often used Title (T)/Last Name (LN) as address terms generally for faculty members and First Name (FN) minimally as a reference term or what he describes as usage in "delayed time".

Afful and Mwinlaaru (2012) focused on the address and reference terms students used for faculty members in a Ghanaian University context. Their result shows that students used three principal forms of address, namely; titles, kinship terms, nicknames as well as personal names when addressing faculty members. One other important thing they observed was that address terms and reference terms functioned as symbols of domination and resistance to domination as well as markers of identities constructed by students.

\subsection{Objective}

The aim of this study was to find out the type of address and reference terms used in classroom discourse between lecturers and students of the University of Cape Coast in Ghana. The study also sought to find out how power dynamics and relationship that exist between the lecturers and students influenced the choice of the address terms.

\subsection{Research Questions}

The study was guided by the following questions:

1) What types of address and reference terms are used by lecturers and students during classroom discourse at the University of Cape Coast?

2) How does power/relationship influence the choice of the address and the reference terms?

\section{Methodology}

The data were taken from 150 participants through interview and observation. Both sessions were audio recorded. Thirty (30) participants each from the five colleges of the university, which constitute 150 participants were selected randomly for the study. From the 150 participants, 120 were students, while the rest 30 were lecturers and instructors (the teaching assistants, MPhil and PhD students contracted to assist in teaching in the departments). Thirty-five (35) lectures in total were recorded by the researchers themselves and by some students, mostly surreptitiously to avoid the observer's paradox. These students usually sat in front of the class so that they could clearly record the lectures. It is important however to note that all the lecturers were given prior notice before the recordings of the various lectures. But at the time of the recording, the lecturers were not aware. For the recordings, a digital audio recorder was used most of the time but on the days where there were multiple lectures running simultaneously, android mobile phones were used to supplement the audio recorders. These phones recorded clearly enough and the recordings we got from them were not different from the ones from the sound recorder. In addition to the recordings, interviews were conducted to give a first-hand account of the power dynamics between the 
teaching staff and the students and reasons behind the choice of the address terms in the classroom. The interviews also helped us understand the dynamics and the thoughts, knowledge and consciousness people have when using the address terms. For the interview, we randomly selected 120 students and 30 lecturers and interviewed them. The respondents were asked simple questions, for example about how they addressed their lecturers, instructors and students during lectures and why they addressed them so.

\section{Data Analysis}

The data were analysed using both qualitative and quantitative methods. The recorded lectures and the interviews were transcribed manually. The transcripts were randomly selected and rechecked independently to ascertain if they matched the audio recordings and the field notes to maintain strict accuracy. This method allowed us to get responses from the participants knowledge on the address terms and the reference terms they used during the classroom interactions. In addition to this, we used statistics to find out the frequencies of the terms used by the respondents. That is, the statistical part was done using simple statistics such as percentages in order to know how the terms varied among the respondents. These were supplemented by an IBM SPSS software version 26, which was used in analysing the collected data quantitatively. Field notes were also used but the analysis focused mainly on the participants' responses.

\section{Results and Discussion}

\subsection{Addressing Lecturers by Students}

This section discusses the type of address terms used by students for their lecturers during classroom interactions at the University of Cape Coast. From the data we identified four main address terms used by students for lecturers during classroom interactions at the university. We identified for example, 1) title + last name (TLN), 2) first name (FN), 3) honorific/Title Only (HON) and 4) avoidance of address term, called zero address term. The details of these are given below. We noticed that students at the University of Cape Coast generally addressed their lecturers during classroom interactions using honourifics or Title Only such as "Sir" and "Madam", Professor (Prof), Doctor (Dr). For example, out of the 130 students interviewed for the study, 87 of them representing $67 \%$ reported to have used the honorifics "Sir", "Madam", Dr or Prof, to address lecturers in the classroom. It appears most of the students preferred this strategy than all the other address terms. Both the recordings and the interviews have shown that students prefer to use honourific terms for their lectureres. For instance, most of the students interviewed reported that they were used to addressing thier teachers using honourifcis since primary schools and it is threfore normal for them to address lectureres at the university with honourific terms. There were some few variations in the use of these terms though. In some cases, some of the students said they used the honorific plus the first name, for exam- 
ple, Madam/Sir plus the first name of the person. This was very few since only two (2) respondents reported this incidence. One of the students had this to say on the use of honorifics.

Extract 1. In class, I always call my lecturers "sir" or "madam". This is because when you call them like that, you don't have to think about being disrespectful since they all like it. Sometimes, I also call them "sir" because I don't know the real names of the lecturers so I say "sir" or "madam" to prevent all these things. (Male Students, History)

Another address strategy we identified in the data was the use of "zero address terms". Many linguists called these "Avoidance terms". For instance, instead of students using first name which is common among students in the USA, or title plus surname of the lecturer, a lot of the students reported they preferred to use actions, clauses or phrases such as raising their hand, or adding a phrase or a clause to this action, for example, "excuse me", "hello", followed by a question' or "I have a question". Here out of the 130 respondents, 30, representing 23\% said they used this strategy. Most of them however said they never thought that this was an address strategy. They just thought it was a way of just asking questions. One student said the following in an interview:

Extract 2. Ei, I didn't know that was an address strategy o. All that I knew was that when I raised my hand in class, I only wanted the teacher to notice that I have a question, not that I was addressing him. But I like doing that a lot and so from now, I will know that I am addressing my teachers when I do this. (Female Student, English)

The use of Honourifics to address senior members or lecturers is not new. McIntire (1972), for example observed that students mostly preferred zero address terms when addressing lecturers, with only a few instances of TLN. But she believe that the use of zero address terms is a symptomatic of confusion of norms. According to Formentelli (2009), the use of avoidance in address term is neutral; it is a deliberate choice not to commit to either of the nominal forms offered by teachers. Its usage may activate pragmatic inferences or feed asymmetry in classroom relations. Students at the University of Cape Coast do not only address their lecturers using honourifics alone.

We also observed that a few of the students used first name (FN) to address their respective lecturers. It is important we note that the use of first names of the lecturers was very limited. A lot of the students felt that the use of this term was a sign of disrespect. In Ghanaian culture, it is a taboo for a younger person to address an older person with their first name and we are therefore not surprised about the result. Bargiela et al. (2002) believe that the use of first name to people, especially strangers is frowned upon in the United Kingdom as many people consider it inappropriate. A student from the Department of English had this to say: Extract 2: "I have never used the first name of the lecturers to call them. Eei, I am even afraid. Someone has gone to study like this and me I will call him 'Kwame'?" (Male student, English) Other extracts below confirm this. 
Extract 3. I always try to call them "Doctor" or "Professor" if the person is one of them. I don't want to offend anybody at all. (Male Student, Chemistry)

Extract 4. I don't like calling lecturers by their first name. No, I don't like it. If they are doctors then I go as Doctor Armah. It will be weird if I call someone like Doctor Armah, just Armah. It will be too heavy in my mouth. (Female student, Social Science)

This brings us to another address term used by the students. Some of the students reported to use title plus last name (TLN) for the lecturers. The use of this term, just like the use of first name, appears to be very limited in the data. Many of the students believed they were not comfortable calling their lecturers by their first names. For example, of the 130 students interviewed, only 5 respondents representing 6.5\% stated that they addressed their lecturers using title plus last name. This has been confirmed by the recordings we got during lectures. Some of these titles they used include "Professor", "Doctor" and Mister. Most of the students stated that the distance between them and the lecturers does not allow them to call the lecturers with their first names. Some mentioned that maybe outside the classroom, "If someone is close to the lecturer, they could use the FN but in the lecture room, they have no right to do that". Some of the respondents stated the following:

Extract 5. Oh no! How can you call your lecturer with his first name? You are not his mates and even if you are very free with him, you can't use his first name to call him in class. Sometimes, some of the lecturers even say that students should use their first names to call them but me I cannot. It is disrespectful for me so me I don't use. (Female Student, English)

The responses provided by students on how they addressed lecturers in the University of Cape Coast are summarised in the Table 1 below:

In order to confirm the use of these terms, we interviewed some of the lecturers. This was to find out their views on how students addressed them in the classroom. Some of the lecturers also mentioned that the avoidance of the use of first name, for instance, could be as a result of the Ghanaian culture of politeness and our cultural values. The following comments were made by some lecturers:

Extract 6. Well, I think very few students call me by my first name. I don't really care if they call me that but very few of them actually do. Usually, they call me Doctor or Sir. (Male lecturer, Social Science)

Extract 7. Oh, I tell them to call me (mentions first name) but they don't. They tend to call me Doctor or Madam. Occasionally, some of them even called me Professor. (Female lecturer, Arts)

It is clear that students used different terms such as FN, TLN, HON and Zero address term when addressing their lecturers during classroom interactions.

Table 1. Addressing lecturers by students.

\begin{tabular}{cccc}
\hline HON/Title Only & TLN & AVOIDANCE & FN \\
\hline 87 respondents 67\% & 8 respondents 6.1\% & 30 respondents 23.1\% & 5 respondents 3.8\% \\
\hline
\end{tabular}


However, the use of Honourifics appears to be dominant among all of these. The use of FN is infrequent and is perceived as abnormal by the majority of informants, since it signals an increase in familiarity.

\subsection{Addressing Nonlecturers by Students}

Students of the University of Cape Coast are not only taught by lecturers. As said earlier in this work, students are also taught by graduate teaching assistants (e.g. MPhil and $\mathrm{PhD}$ ) whom the university engages to teach. Interestingly, the address terms used by students for these instructors were different from those of the lecturers. In most cases, the students are seen to be closer to the instructors than the lecturers. This means that they are more comfortable around the instructors than they are with the lecturers. Their closeness with the instructors are seen in the types of address terms the students used for the instructors. The respondents were also asked to describe how they referred to some of these instructors during classroom interactions. Their responses are summarised in the Table 2 below:

The information in Table 2 shows a different picture from the address strategies students used for the lecturers. The choice of the address terms used to address non-lecturers during classroom interactions though are not quite different from those of lecturers, their percentages differ. From the table, we see that the use of avoidance terms and fort name appear to be dominant among the four terms. Even though they also used honourific term, the choice was not as high as it was with the lecturers. The dominant use of first names for nonlecturers could be that the students are closer to the non-lecturers than to lecturers. The students are very close to the nonlecturers and so used a more friendly types of the address terms mainly the first names of the instructors. Another thing that stood out in the use of the address terms for the two groups of teachers in the University of Cape Coast is the high usage of avoidance strategies. Most of the students preferred to use the avoidance terms. This appears to be used a lot since most of the students feel they do not have to think about the right terms to use before addressing them. On the use of the FN, most of the students said it was not intentional but the reason for the usage was mainly because of how the instructors were first introduced or how they introduced themselves when they come to the class. One of the students had this to say:

Extract 8. It depends on how they' ve [i.e. instructors] been introduced. Usually if they've introduced themselves by their first name, $P$ Il call them by their first name, otherwise it $d$ be doctor or mister if that's how they've been introduced. (Male student, Mathematics)

Table 2. Addressing nonlecturers/instructors by students.

\begin{tabular}{cccc}
\hline HON & TLN & AVOIDANCE & FN \\
\hline $\begin{array}{c}\text { 34 respondents } \\
\text { representing (26.2\%) }\end{array}$ & $\begin{array}{c}\text { 6 respondents } \\
\text { representing 4.6\% }\end{array}$ & $\begin{array}{c}\text { 49 respondents } \\
\text { representing 37.7\% }\end{array}$ & $\begin{array}{c}\text { 41 respondents } \\
\text { representing (50\%) }\end{array}$ \\
\hline
\end{tabular}


It is clear that students employ different address terms during classroom interactions to address both lecturers and non-lecturers. But the choice depends on the relationship between the students and the instructor. We have observed that in classroom interactions, lecturers with higher academic qualifications were addressed generally with honourifics or Title only, while nonlecturers who are lower in rank than lecturers were addressed generally with first names and avoidance terms. Below are some of the excerpts from the recordings:

Extract 9. Sir, is there a way the plants can reproduce in a low to medium enclosed garden? (Student to lecturer)

To explain this further, a list of some of the address terms recorded in the audio are presented below:

Table 3 has shown the live recordings of some of the address terms used by students for their lecturers and nonlecturers during some of the interactions in the classrooms. The next section discusses how lecturers addressed students during lectures.

\subsection{Addressing Students by Lecturers}

Power dynamic in this current discussion is also vertical, but this time from a higher rank to lower one. Here, the lecturers have more power than the students and so this is seen in how the lecturers addressed the students. Both the interview and the lectures recorded have shown that lecturers at the University of Cape Coast generally addressed students in the classroom using their first names. But we noticed also that they made use of the avoidance strategy just like the students, although the expressions they used were somehow different. For example, we observed terms such as young man, course rep, young lady, sweetheart, and so on. These phrases might perhaps be employed by the lecturers who might not know the names of the students. The use of the avoidance strategy creates a kind of familiarity between the lecturers and the students and is thus more informal than the others. The extracts below illustrate some of these:

Extract 10. Some lecturers go like "young lady" though no one will turn around. (Female student, Business)

Extract 11. I know a lecturer who would always say "young man" or "young lady" when they don't know the name of the student. (Male student, French)

Extract 12. Oh, it is normal for some of the lecturers to call you with an endearment term or even your complexion. Some lecturers usually call females "sweetheart" or even "the fair coloured lady." Students see these to be normal and sometimes even funny. (Female student, English)

The use of these terms may be influenced by personal relationships that exist between students and lecturers. They could also be used to make the students feel good so that they could answer the questions or performed the tasks they were given. The use of the terms again show a good level of informality between students and lecturers in the academic setting at the University. This means that the strict way of life that was in the universities some years ago is gradually being 
Table 3. Addressing lecturers and nonlecturers by students.

\begin{tabular}{ll}
\hline \multicolumn{1}{c}{ Address Terms } & \multicolumn{1}{c}{ Examples } \\
\hline TLN & Prof. K., Prof. K.K., Prof. O.A., Dr. K.B., Dr. A.M., Mr. N., Mr. A. \\
HON, Title Only HON + FN & Sir, Madam, Prof., Dr., Sir A, Madam D., etc. \\
FN & Maxwell, Fifi, Baah, Kwame, Hannah, Genevieve, etc. \\
& $\begin{array}{l}\text { Excuse me Sir, I have a question, Please, I have a question, students } \\
\text { AVOIDANCE }\end{array}$ \\
\hline
\end{tabular}

Table 4. Addressing students by lecturers.

\begin{tabular}{cl}
\hline Address Terms & \multicolumn{1}{c}{ Examples } \\
\hline First Names & Georgina, Nana, Afrakomaa, Pokuah, Adu, Nana Takyia, Musah, etc. \\
Avoidance & $\begin{array}{l}\text { Course rep, group leader, the tall guy, guys, fair girl, sweetheart, dada cash, young } \\
\text { man, lady, the one who has raised the hand, the one sitting on the left, etc. }\end{array}$ \\
\hline
\end{tabular}

reduced. An interview with some lecturers on their choice of these address terms confirms this:

Extract 14. I usually call my students with their first names because I feel that is the best thing to do. I can't call them by honorifics. It will be weird to call a student Mr Boah. So for me, that is the normal way to go. (Male Lecturer, French)

Extract 15. Interesting, I tend to use a lot of address terms for my students. Sometimes, you can hear me calling some ladies "red girp" or "charcoal girp". My students know it is a joke so we all go with it. There are also cases I call some students "rastafarians", especially the guys but like the females, they all know it is a joke so no one takes it personal. (Lecturer, Business)

It is clear from the above discussion, that the academic setting has made certain address terms normal and so most of the students and lecturers abide by them. In some cases too, the lecturers and students used their personal terms to address each other. Usually, all of them accepted and understood them, so there were no issues and problems involved. There were also other informal expressions that were used occasionally. Some of these are presented in the Table 4 below:

The use of first names to address people generally reduces the interpersonal relationships between people (Formentelli, 2009; Afful \& Mwinlaaru, 2012). Thus students avoid these awkward feelings and go for the more formal one while lectures, go for the informal ones.

\section{Conclusion}

This paper examined address terms used during classroom interactions between students and lecturers at the University of Cape Coast. It further looked at how power and relationship influenced the use of the address terms. The study has revealed four principal address terms: 1) Honourific or Title only, 2) First name, 3) Title plus last name and 4) zero address term (avoidance term) used during 
classroom interactions between students of University of Cape Coast and their teaching staff. We noticed that the kind of address terms used by students to address their lecturers in the classroom was different from those used by lecturers for their students. For example, we observed that students mostly addressed their lecturers using honourific or Title only and zero address term or what is called avoidance term. The use of first names and titles plus last names was very infrequent. For example, only a few students reported having used these terms for the lecturers. For nonlecturers, most of the students reported having used their first names and avoidance terms. No students used Title only or Title plus last name to address nonlecturers. Lecturers however addressed their students mainly using their first names and avoidance term. No lecturer used Title only or Title plus last name to address their students. It, therefore, appears that the use of avoidance term was dominant among all the people.

The obvious reason for the choice of some of the terms, for example, the use of the honourific or Title only was cultural. The choice was also significantly influenced by the kind of relationship between the interactants. In Ghanaian culture, for example, a younger person is expected to address an older person according to his or her status or title and not his or her first name. An older person, on the other hand, could address a younger person with his or her first name. Since lecturers are older and higher in status than the students, it is prudent that they are addressed accordingly and vice versa. We also noticed that the use of honourific or Title only was due to the fact that in Ghana many students address their teachers with honourific from basic schools. Since they are used to this term from their early stage of education, it becomes easier to use it even at a higher level of their education.

The reason for the use of avoidance term was however different. We observed that students avoided any of the terms and resorted to the zero term if they did not know the lecturers' academic qualifications. The use of the avoidance term was therefore to prevent embarrassment. They did not want to address their lecturers using inappropriate terms, so they resorted to the use of phrases and clauses instead. A lot of the students reported that with the use of the avoidance term, they did not have to think about the status of the lecturer before addressing him or her. The reason for using the zero term by lecturers for their students was interestingly different. For instance, the use of the zero term by lecturers was believed, bridged the gap between the lecturers and their students. It makes the relationship between the lecturers and their students closer.

It is clear that the kind of address terms used between lecturers and students during classroom interactions in the university will significantly depend on two things: 1) culture and 2) relationship. We noticed that Ghanaian culture significantly influences the way individuals are addressed in Ghana and this has implications for how lecturers and students addressed one another in the classroom. The asymmetrical relationship exists in the Ghanaian cultural system and it extends to the academic setting. The address terms express unequal levels of formality and informality in the relationship between students and teachers in the 
classroom. This inequality is however, seen to be normal to the two parties involved in the classroom. Students and faculty members try to negotiate around this principle in the choices they make regarding the address practices in the classrooms at the university. That is, both the students and the teaching staff are aware of each other's face needs and are cautious about saving it. They, therefore, try as much as possible to use the best polite system that is available to them at any particular point in time.

Finally, employing gestures as a form of address signals the uneven distribution of power in the dyad and of the hierarchical structure of academic interactions.

\section{Conflicts of Interest}

The author declares no conflicts of interest regarding the publication of this paper.

\section{References}

Afful, J. B. A., \& Mwinlaaru, I. N. (2012). When Sir and Madam Are Not: Address Terms and Reference Terms Students Use for Faculty in a Ghanaian University. Sociolinguistic Studies, 6, 491-517. https://doi.org/10.1558/sols.v6i3.491

Bargiela, F., Corinne B., Gokzadze, L., Abdurrahman H., Mills, S., \& Rukhadze, N. (2002). Ethnocentrism, Politeness and Naming Strategies. Working Papers on the Web. https://extra.shu.ac.uk/wpw/politeness/bargiela.htm\#

Biber, D., Johansson, S., Leech, G., Conrad, S., \& Finegan, E. (1999). Longman Grammar of Spoken and Written English. Essex: Pearson Education Limited.

Brown, R., \& Ford, M. (1961). Address in American English. Journal of Abnormal and Social Psychology, 62, 375-385. https://doi.org/10.1037/h0042862

Brown, R., \& Gilman, A. (1960). The Pronouns of Power and Solidarity. In T. A. Sebeoki (Ed.), Style in Language (pp. 253-276). Cambridge, MA: MIT Press.

Clark, C., \& Clark, I. (2008). Exploring and Exposing a Gap in L2 Research: How Socio-Linguistic Roles and Relationships Facilitate or Frustrate Second Language Acquisition. Journal of the Spanish Association of Anglo-American Studies, 30, 101-113.

Clyne, M. (2009). Address in Intercultural Communication across Languages. Intercultural Pragmatics, 6, 395-409. https://doi.org/10.1515/IPRG.2009.020

Cook, M. (2014). Beyond T and V-Theoretical Reflections on the Analysis of Forms of Address. American Journal of Linguistics, 3, 17-26.

Dickey, E. (1997). Forms of Address and Terms of Reference. Journal of Linguistics, 33, 255-274. https://doi.org/10.1017/S0022226797006488

Dunkling, L. (1990). A Dictionary of Epithets and Terms of Address. London: Taylor \& Francis Routledge.

Formentelli, M. (2009). Address Strategies in a British Academic Setting. Pragmatics, 19, 179-196. https://doi.org/10.1075/prag.19.2.02for

Helmbrecht, J. (2013). Politeness Distinctions in Pronouns. In M. S. Dryer, \& M. Haspelmath (Eds.), The World Atlas of Language Structures Online. Leipzig: Max Planck Institute of Evolutionary Anthropology.

McIntire, M. L. (1972). Terms of Address in an Academic Setting. Anthropological Lin- 
guistics, 14, 286-291.

Murphy, G. L. (1988). Personal Reference in English. Language in Society, 17, 317-349. https://doi.org/10.1017/S0047404500012938

Murray, T. E. (2002). A New Look at Address in American English: The Rules Have Changed. Names, 50, 43-61. https://doi.org/10.1179/nam.2002.50.1.43

Oyetade, S. O. (1995). A Sociolinguistic Analysis of Address Forms in Yoruba. Language in Society, 24, 515-535. https://doi.org/10.1017/S004740450001900X

Wierzbicka, A. (2003). Cross-Cultural Pragmatics. Berlin: Walter de Gruyter Inc. https://doi.org/10.1515/9783110220964 